\title{
Mechanism of $\mathrm{PbSe}_{y} \mathrm{~S}_{1-y}$ Film Formation in Chemical Deposition from Aqueous Solutions
}

\author{
A. S. Katysheva, V. F. Markov, and L. N. Maskaeva \\ Ural Federal University named after the first President of Russia B.N. Yeltsin, Yekaterinburg, Russia \\ Received July 20, 2012
}

\begin{abstract}
The growth mechanism of $\mathrm{PbSe}_{y} \mathrm{~S}_{1-y}$ films has been studied upon chemical deposition from aqueous solutions using scanning probe microscopy. A comparative morphological analysis of layers deposited at the initial growth stages and the use of fractal formalism shows that the formation of films of PbS, $\mathrm{PbSe}$, and $\mathrm{PbSe}_{y} \mathrm{~S}_{1-y}$ substitutional solid solutions involves cluster-cluster aggregation with self-organization elements.
\end{abstract}

DOI: $10.1134 /$ S0036023613070127

Progress in the field of micro- and nanoelectronics is due to the creation of novel semiconductor materials and the development of methods for controlling their functional properties. One very promising method for manufacturing chalcogenide material films is hydrochemical deposition thanks to its high economy, technological simplicity, productivity, and flexibility in the context of controlling the composition and properties of deposited layers. Furthermore, this method, which represents soft chemistry, allows synthesizing compounds of complex composition, in particular, substitutional solid solutions [1].

Substitutional solid solutions in the $\mathrm{PbS}-\mathrm{PbSe}$ system are of most applied importance. $\mathrm{PbSe}_{y} \mathrm{~S}_{1-y}(0 \leq$ $y \leq 1)$ solid solution films are useful as materials for detectors and photoreceiver devices having a spectral sensitivity range $(0.4-4.5 \mu \mathrm{m})$, semiconductor lasers of the infrared range, and chemical sensors [2-4]. However, most publications concerning the hydrochemical deposition of metal chalcogenide films primary deal with electrophysical properties. Proper attention has not been paid to film nucleation and growth mechanisms, which meanwhile have a very important effect on the composition, structure, and functional properties of the resulting materials, in particular in the $\mathrm{PbSe}_{y} \mathrm{~S}_{1-y}$ system.

Currently, researchers consider the formation of films and their growth upon hydrochemical deposition of metal sulfides and selenides by thio- and selenoamides mainly in the frames of the following two mechanisms: an ion-molecule mechanism and an adsorption-aggregation mechanism [5-7]. The opposition of these mechanisms is likely due to the great diversity of factors that influence hydrochemical deposition. In our opinion, an operation of either of the two mechanisms cannot be ruled out in film nucleation and growth, and the only what can be told about is the dominant role of either under some settings.
The existing classical theories of crystal formation developed by Kossel [8], Stranski [9], Frank [10], and Volmer [11], which study the process under near-equilibrium conditions, virtually ignore the role and composition of the medium and do not explain a considerable divergence of experimental data on phase formation in reaction mixtures. Operating with discrete atoms and molecules in considering crystal growth mechanisms is valid in models for initial stages that involve weak interactions and occur under low supersaturations as regards the newly forming phase. Heavily nonequilibrium conditions that appear in reaction systems during the hydrochemical synthesis of metal chalcogenide films and their base solid solutions cannot rule out coming into play of other growth mechanisms. It is important to recognize that the film growth process is to be classified as a volume phenomenon, rather than a surface one, because of an active participation of the bulk of the reaction mixture. It had been established $[12,13]$ that the formation of a metal chalcogenide phase in the solution bulk during hydrochemical synthesis is accompanied by the accumulation of their colloidal fraction in the bath. Proceeding from the physicochemical contents of the process, one may assume that they would also play an active role in further film formation.

A considerable promise in disclosing the formation mechanism of a new phase under settings far from thermodynamic equilibrium have recently been opened due to the use of fractal formalism [14]. Fractal formalism has been used to consider films formation for metal sulfides and their base solid solutions during hydrochemical deposition $[15,16]$. In terms of fractal formalism, we may suggest that the key role in the hydrochemical deposition of films belongs to primary structural units that are formed in the system, namely fractal clusters which can be structured and compacted colloidal solution species. These species 
constitute the base for the newly forming phase. In this context, nanosized colloidal particles should be regarded as the major primary unit in the hydrochemical synthesis of metal sulfides and selenides. Their aggregation and reorganization give rise to a branched structure that fully corresponds with the principles of fractality. We will also take into account that colloidal particles themselves correspond with all properties of fractal elements.

Here we study the formation mechanism of $\mathrm{PbSe}_{y} \mathrm{~S}_{1-y}(0 \leq y \leq 1)$ films during hydrochemical deposition by means of a comparative morphological analysis of layers deposited at the initial growth stages and in terms of fractal formalism.

\section{EXPERIMENTAL}

The subjects of our study were thin films of lead sulfide, lead selenide, and their substitutional solid solutions $\mathrm{PbSe}_{y} \mathrm{~S}_{1-y}$. The hydrochemical deposition was carried out at $353 \mathrm{~K}$ for $90 \mathrm{~min}$ from a citrate-ammoniate system that comprised a lead salt, sodium citrate, ammonium hydroxide, ammonium iodide, sodium sulfide, and thio- and selenocarbamides. When initial film growth stages were studied, the deposition time was varied from 10 to $600 \mathrm{~s}$. The substrates used in film deposition were ST-150-1 pyroceram platelets with sizes of $30 \times 24 \mathrm{~mm}$. The substrate surface was degreased with a hot (323-343 K) chromate solution and slightly etched with dilute $(1: 20)$ hydrofluoric acid. Then the substrates were placed into a reaction mixture contained in a molybdenum glass reactor. The reactor was mounted inside a LOIP LT-112a thermostat where the temperature maintenance accuracy was $\pm 0.1 \mathrm{~K}$. A strictly definite order of combining the reagents was provided in all experiments.

Film surfaces were studied with a FemtoScan scanning probe microscope (Advanced Technologies Center, Moscow State University, Moscow) in the resonance atomic-force microscopy mode. Silicon cantilevers $f \mathrm{pN} 11$ with a curvature radius of the probe tip of less than $25 \mathrm{~nm}$ and a resonance frequency of $152 \mathrm{kHz}$ were used in surface scans.

\section{RESULTS AND DISCUSSION}

The composition, structure, and morphology of deposited $\mathrm{PbSe}_{y} \mathrm{~S}_{1-y}$ films are considered elsewhere [17]. As a result of X-ray analysis, we discovered that the deposited layers consist of two phases, i.e., contain simultaneously $\mathrm{PbSe}_{y} \mathrm{~S}_{1-y}(0<y<0.9)$ solid solutions based on both $\mathrm{PbS}$ and $\mathrm{PbSe}$. The lead selenide content of the $\mathrm{PbSe}_{y} \mathrm{~S}_{1-y}$ solid solution was an extreme function of the chalcogenizer concentration in the reaction mixture. In addition, an increase in selenocarbamide concentration in the reaction mixture, with thiocarbamide content therein being constant, resulted in a change in the phase ratio in the films: the $\mathrm{PbS}$-based solution decreased in concentration, whereas the PbSe solid solution increased in concentration.

As the selenocarbamide concentration in the reaction mixture increased, the deposited layers experienced a considerable morphological alteration, in particular, a reduction in surface roughness and mean grain size. To exemplify, Fig. 1 show $2 \times 2 \mu \mathrm{m}$ surface scans of a PbS film (Fig. 1a), a PbSe film (Fig. 1c), and a codeposited film containing $\mathrm{PbSe}_{0.07} \mathrm{~S}_{0.93}$ solid solution (75 wt \%) and $\mathrm{PbSe}_{0.85} \mathrm{~S}_{0.15}$ solid solution (25 wt \%) (Fig. 1b). The deposition time was $90 \mathrm{~min}$. The fractal-cluster architecture of the layers is distinct, implying the aggregation mechanism of their formation.

In order to study the film growth mechanism upon hydrochemical deposition, comparative studies of surfaces of $\mathrm{PbS}, \mathrm{PbSe}$, and $\mathrm{PbSe}_{y} \mathrm{~S}_{1-y}$ substitutional solid solution layers deposited at the initial synthesis stage were carried out using a scanning probe microscope. Figure 2 shows the surface morphology evolution of a film in the $\mathrm{PbS}-\mathrm{PbSe}$ system deposited from the citrate-ammoniate system within a period from 10 to $120 \mathrm{~s}$.

One can easily see that, in $10 \mathrm{~s}$ from the onset of the process, a layer of uniform spherical particles 100-200 nm in size is formed on the surface of a pyroceram substrate; by the 20th second, these particles are joined together to form aggregates of $300-400 \mathrm{~nm}$ in size. In the scan that demonstrates the formation of a $\mathrm{PbS}-$ $\mathrm{PbSe}$ film by the 45th second of the process, some grains experience a considerable shape distortion. These grains acquire extended shapes reaching 350$600 \mathrm{~nm}$ in length. Simultaneously, globules with diameters of about $50-70 \mathrm{~nm}$ are observed in the plane of the substrate.

As estimated by the 60th second, spherical aggregates in the film increase to $60-240 \mathrm{~nm}$. An appreciable surface leveling of the layer (the appearance of continuity) is noticed for a film that has been formed by the 90th second of the synthesis. The surface of this film is formed by grains tightly adhering to one another and having sizes of 50-100 nm. In $120 \mathrm{~s}$ of hydrochemical synthesis, particles 35-90 nm inclined to faceting and larger aggregative entities of up to $300-$ $500 \mathrm{~nm}$ may be recognized on the surface.

In terms of the fractal-cluster approach to metal sulfide and selenide film formation, the fractal dimension $D$ is known to be an important tool to characterize the layer growth mechanism in hydrochemical deposition [1]. This parameter characterizes the degree of substrate surface coverage by the film material. In order to determine the fractal dimensions of films, we carried out computer processing of micrographs of $\mathrm{PbS}, \mathrm{PbSe}$, and $\mathrm{PbSe}_{y} \mathrm{~S}_{1-y}$ substitutional solid solution layers during the active growth period using Fractalyse-2.4 software. The fractal dimension calculations comprised the division of the field of a macrograph into cells with a side $a$ having various sizes and counting their number occupied with clusters $N$. The 

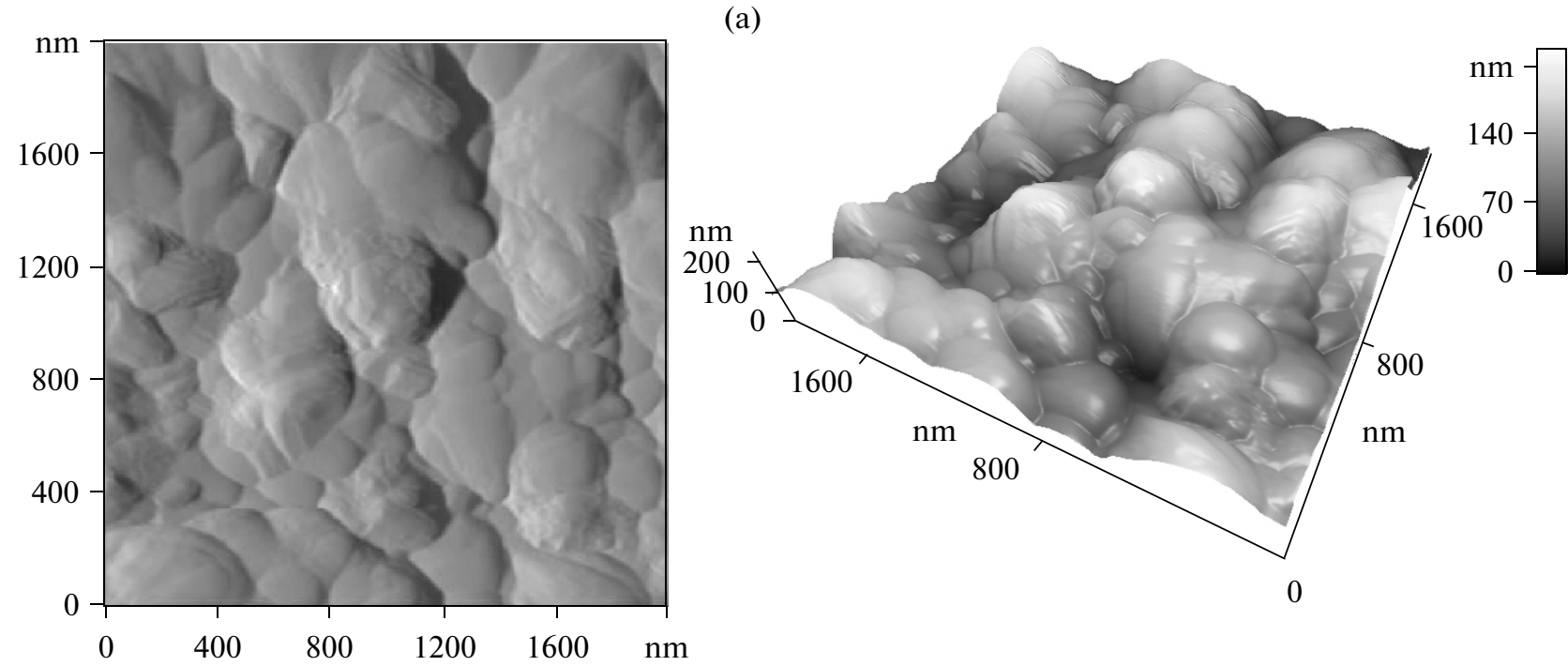

(b)
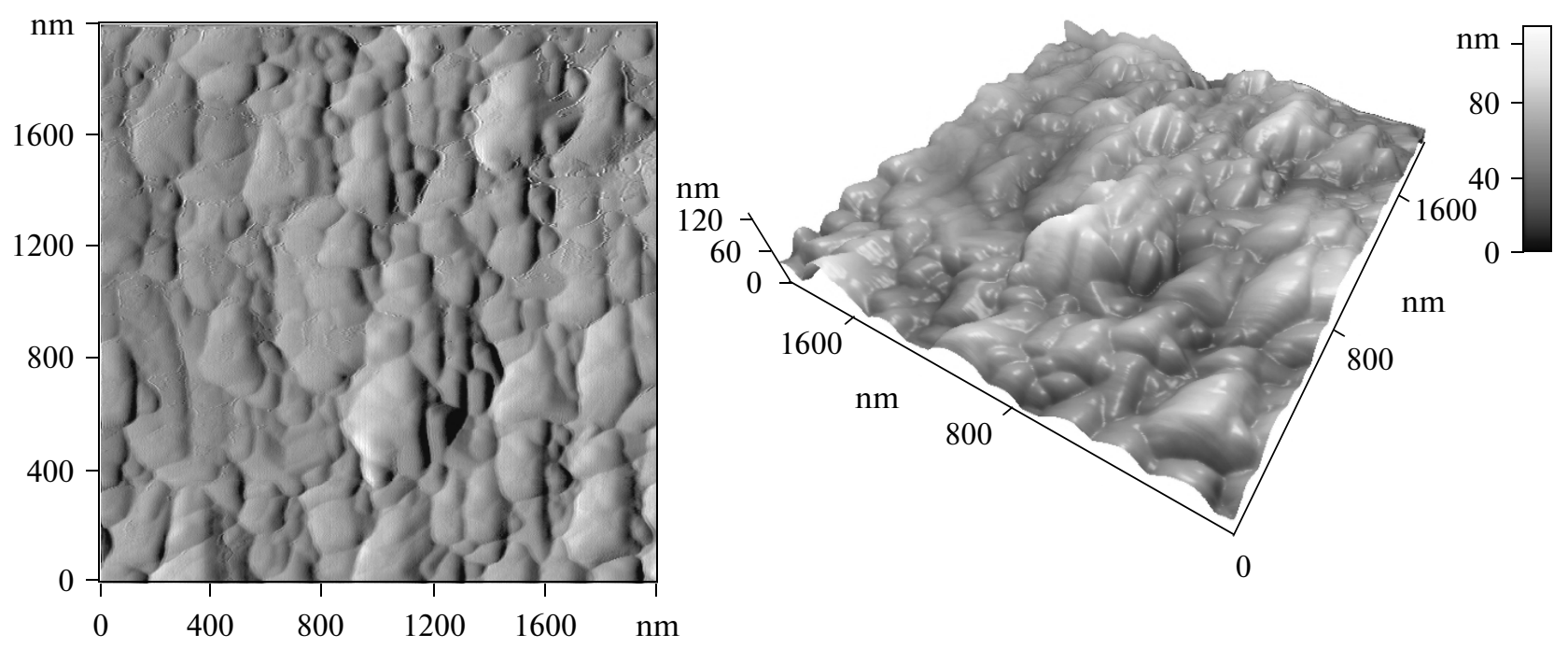

(c)
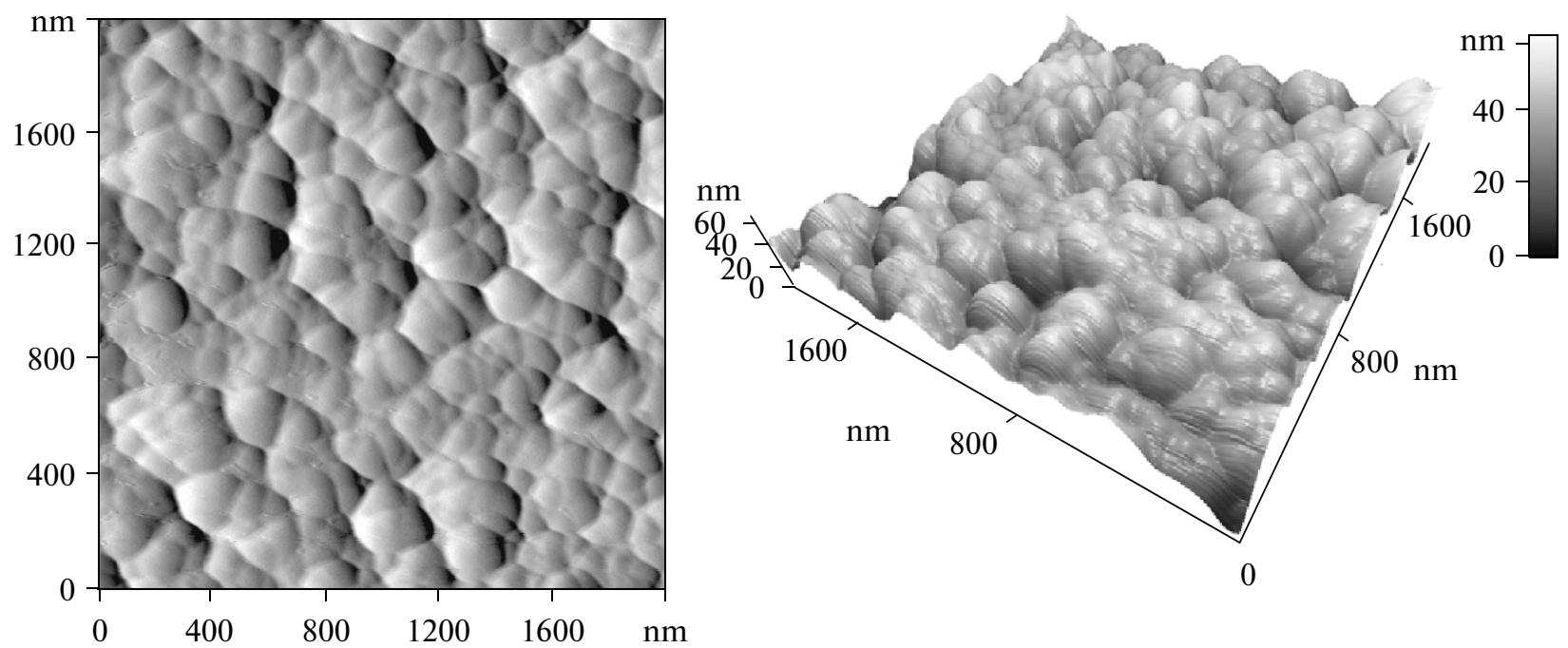

Fig. 1. AFM surface images of (a) a $\mathrm{PbS}$ film, (c) a PbSe film, and (b) a film containing $\mathrm{PbSe}_{0.07} \mathrm{~S}_{0.93}$ solid solution (75 wt \%) and $\mathrm{PbSe}_{0.85} \mathrm{~S}_{0.15}$ solid solution (25 wt \%). Deposition time: 90 min. Scan size: $2 \times 2 \mu \mathrm{m}$. 


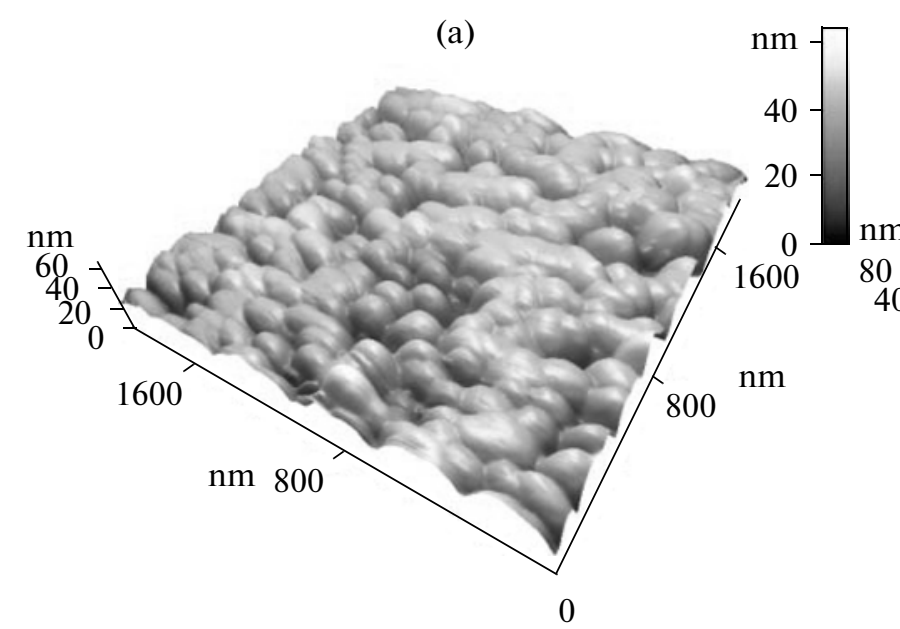

(c)

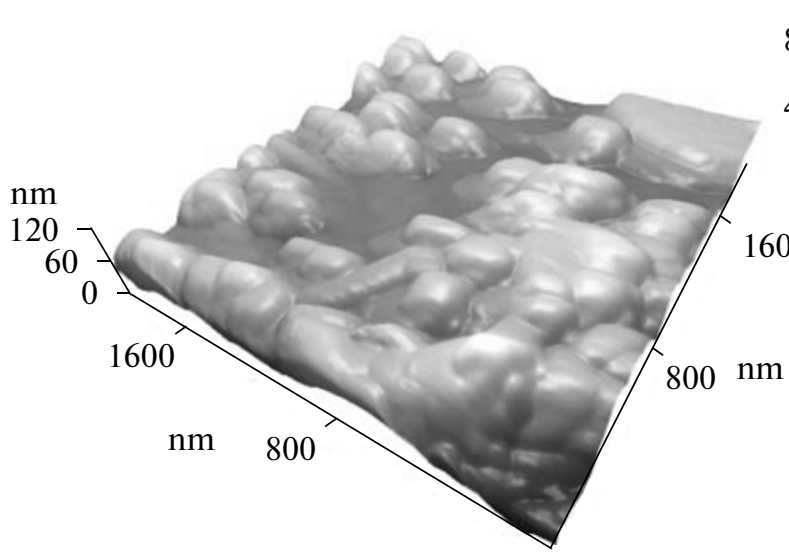

0

(e)
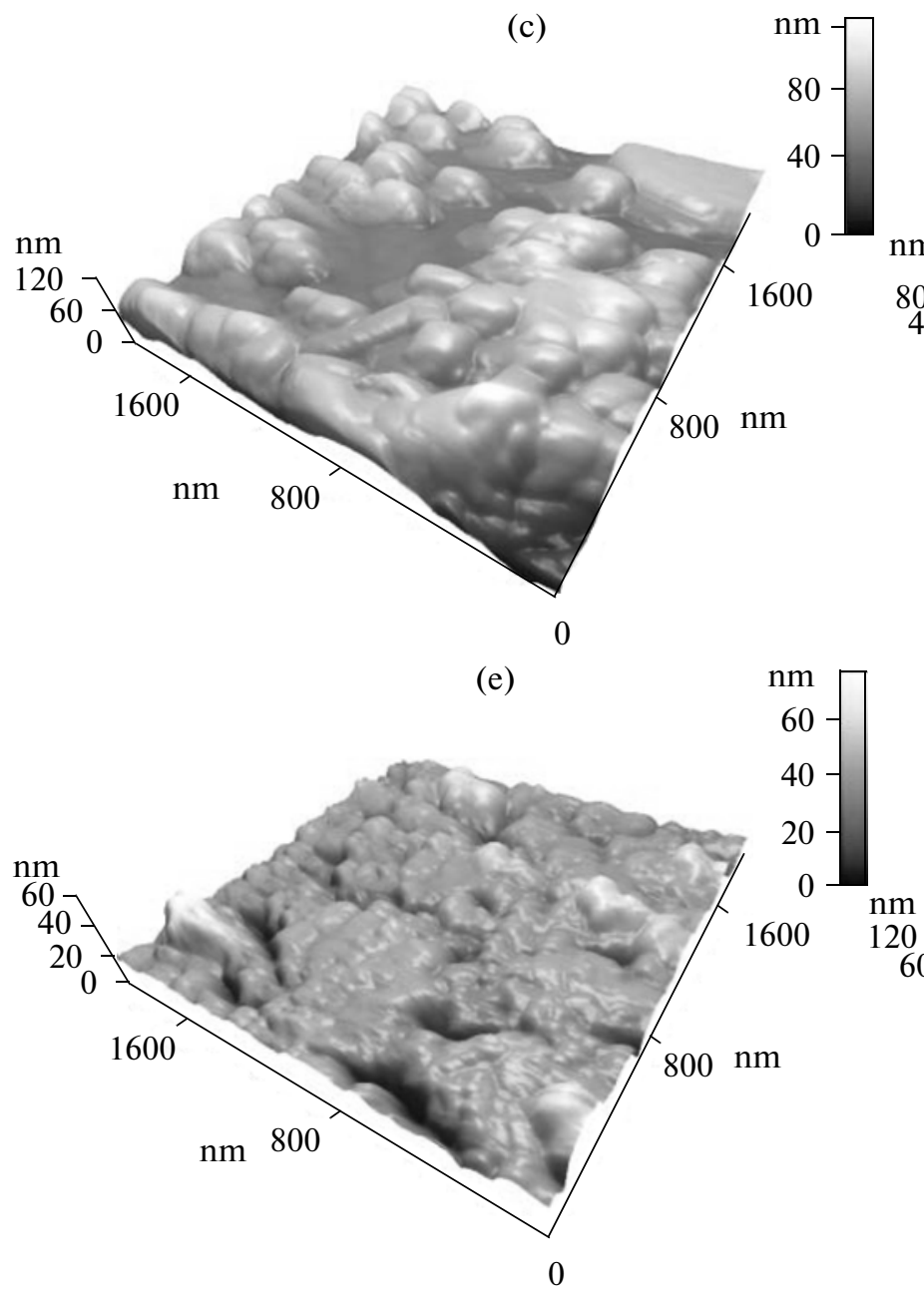

(b)

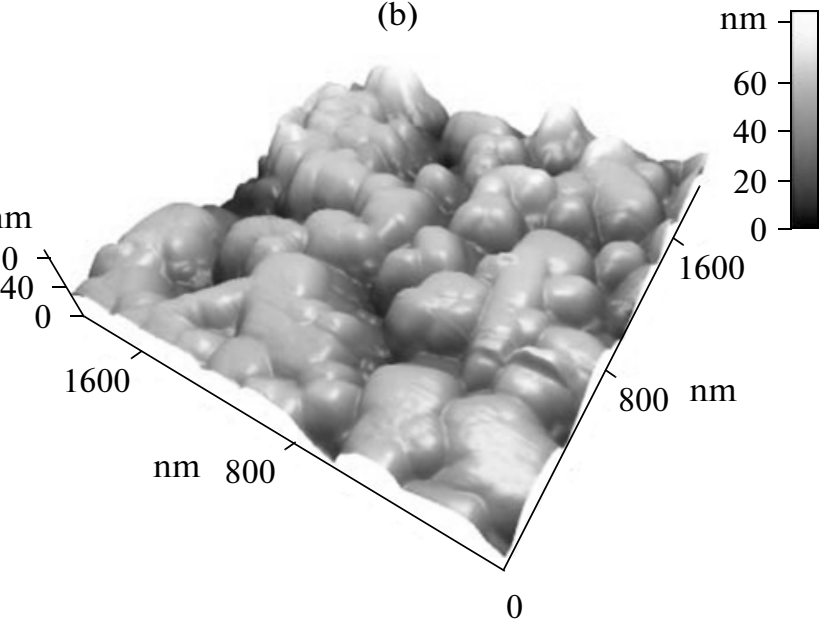

(d)

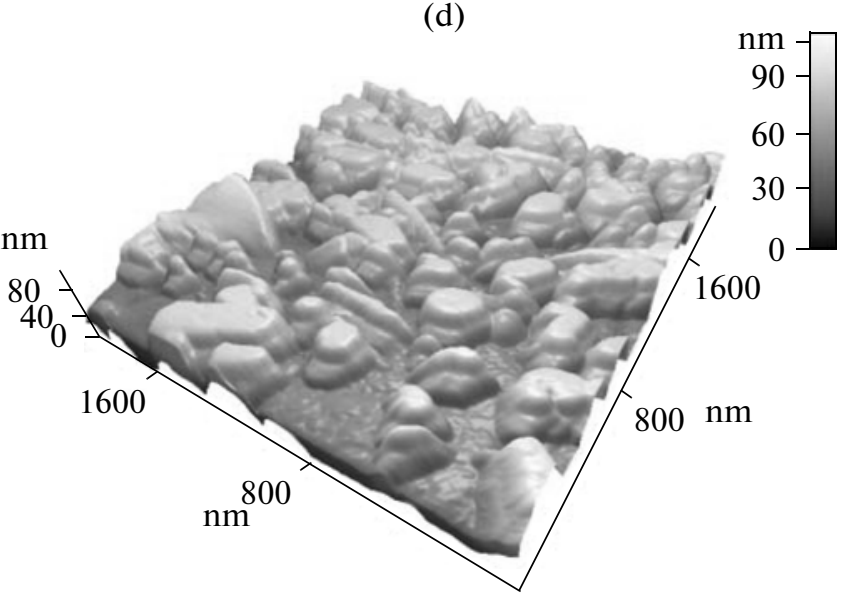

(f)

0

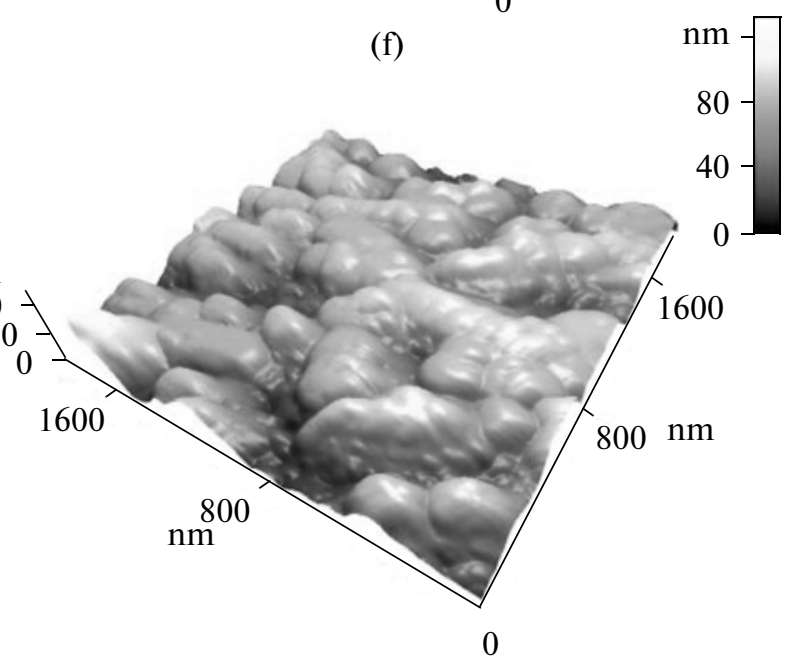

Fig. 2. AFM surface images of $\mathrm{PbSe}_{y} \mathrm{~S}_{1-y}$ solid solution films synthesized with the synthesis time, in seconds, of (a) 10, (b) 20, (c) 45 , (d) 60 , (e) 90 , and (f) 120 . Substrate: pyroceram. Scan size: $2 \times 2 \mu \mathrm{m}$.

value of $D$ was found as the slope of the $\log N$ versus $\log a$ plot [18].

To exemplify, Fig. 3 shows the graphical determination of fractal dimensions for a $\mathrm{PbS}$ film (deposition time: $5 \mathrm{~min}$ ), a PbSe film (deposition time: $45 \mathrm{~s}$ ), and a codeposited $\mathrm{PbS}-\mathrm{PbSe}$ layer (deposition time: $60 \mathrm{~s}$ ). The resulting fractal dimension values, which are found in the table, are less than two for all of the aforementioned films and fall within the range $D=1.76-$ 1.78. These values for film formation, according to 


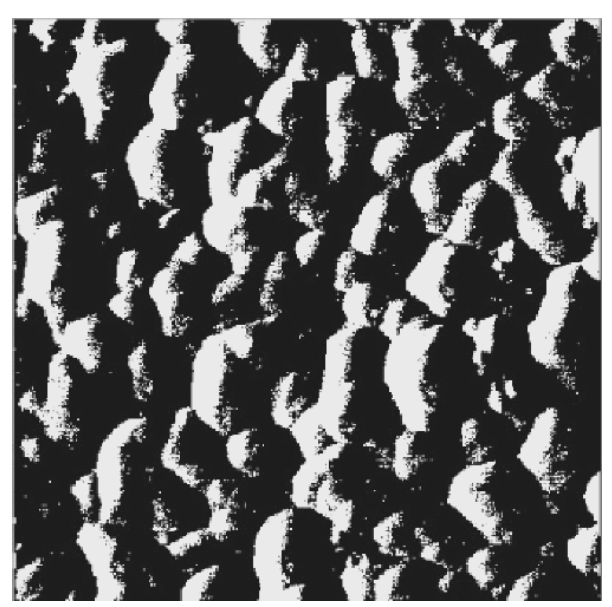

(a)

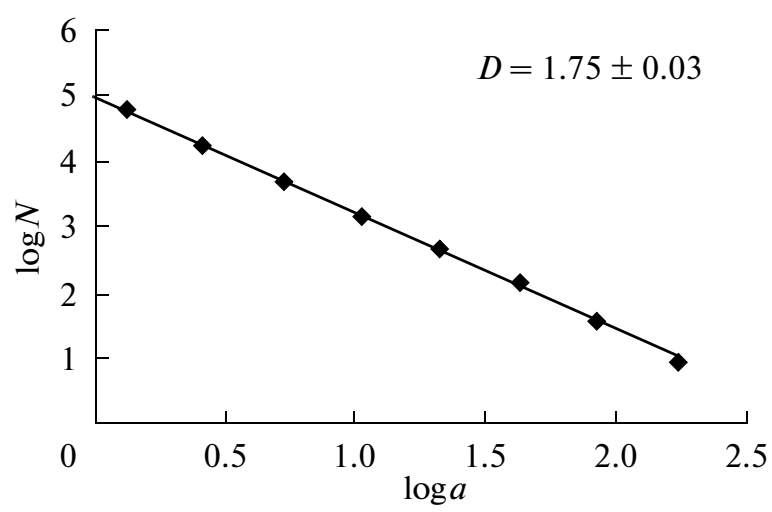

(b)
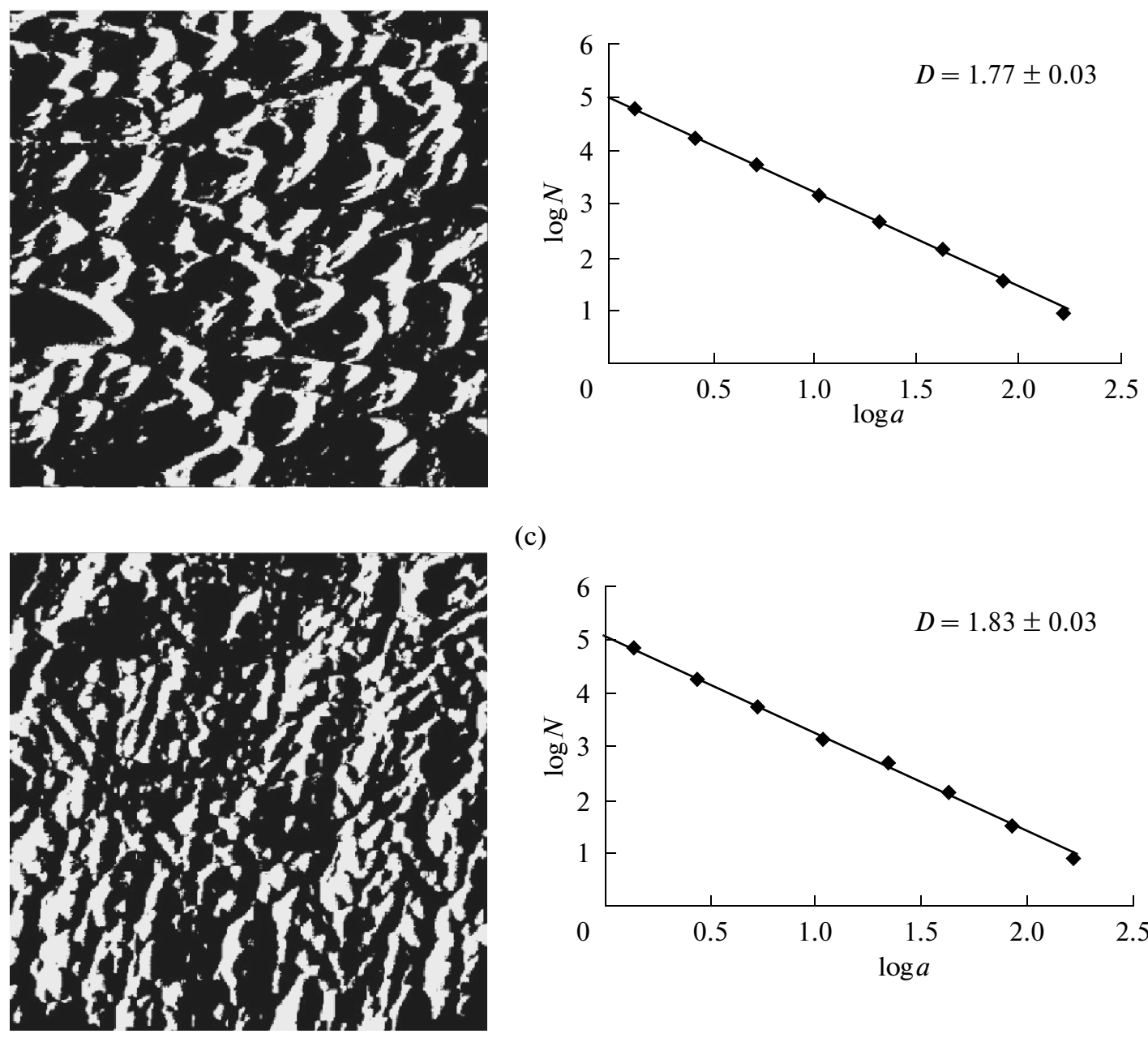

(c)

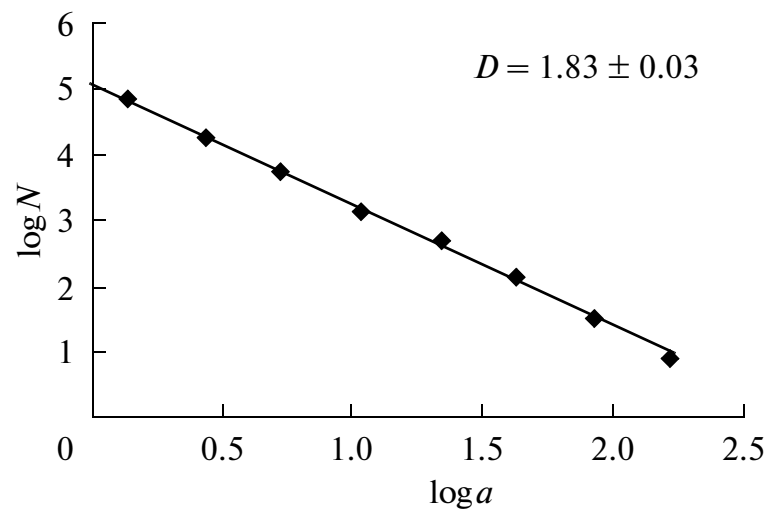

Fig. 3. $2 \times 2 \mu \mathrm{m}$ AFM images of (a) a PbS film synthesized in $5 \mathrm{~min}$, (c) a PbSe film synthesized in $45 \mathrm{~s}$, and (b) a PbSe $y \mathrm{~S}_{1-y}$ solid solution film synthesized in $60 \mathrm{~s}$, and determination of their fractal dimensions.

[14], correspond to the cluster-cluster (CCA) aggregation mechanism with Brownian motion with a sticking probability close to unity. This model suggests a scaled hierarchy of film formation: rather small fractal clusters are formed at the first stage to be joined into larger aggregates at subsequent stages.

Some oscillations in fractal dimension can be noted depending on the synthesis time, which consist 
Fractal dimension of films, $D$

\begin{tabular}{c|c|c|c|c|c}
\hline \multicolumn{2}{c|}{$\mathrm{PbS}$} & \multicolumn{2}{c|}{$\mathrm{PbSe}_{y} \mathrm{~S}_{1-y}$} & \multicolumn{2}{c}{$\mathrm{PbSe}$} \\
\hline $\begin{array}{c}\text { synthesis } \\
\text { time, min }\end{array}$ & $D$ & $\begin{array}{c}\text { synthesis } \\
\text { time, } \mathrm{s}\end{array}$ & $D$ & $\begin{array}{c}\text { synthesis } \\
\text { time, } \mathrm{s}\end{array}$ & $D$ \\
\hline 1 & 1.83 & 10 & 1.84 & 10 & 1.88 \\
2 & 1.76 & 20 & 1.78 & 15 & 1.67 \\
3 & 1.62 & 30 & 1.64 & 20 & 1.72 \\
5 & 1.75 & 45 & 1.82 & 30 & 1.80 \\
7.5 & 1.78 & 60 & 1.77 & 45 & 1.83 \\
10 & 1.80 & 90 & 1.85 & 60 & 1.69 \\
& & 120 & 1.73 & & \\
Average & 1.76 & & 1.78 & & 1.77 \\
\hline
\end{tabular}

in an alternation of periods of some increase and some decrease. This can be associated with the operation of other film growth mechanisms, in particular, aggregation by the cluster-particle aggregation (diffusion limited aggregation (DLA)) mechanism, or with a reduction in the particle sticking probability upon mutual touching (reaction-limited cluster aggregation (RLCA) model). The results are convincing in that aggregation is the dominant film formation mechanism during hydrochemical deposition.

In light of the above results and those from $[1,15$, 16], we may infer that following film growth mechanism is involved in the hydrochemical deposition of lead sulfide and lead selenide. Primary clusters that have been formed in the bulk of the reaction mixture are anchored to the non-uniform substrate surface to progressively cover the entire surface. Then, these clusters are enlarged due to joining together of adsorbed particles and attachment of new cluster species from solution. As a result, the substrate surface is entirely covered with cluster species of higher scaled hierarchy. In this way a continuous layer is formed for microparticles from solution to be deposited over it. The process has a well-defined periodical self-organization character.

\section{ACKNOWLEDGMENTS}

This study was supported by the support for young scientists of the Ural Federal University in the frame of the development program of the Ural Federal University.

\section{REFERENCES}

1. V. F. Markov, L. N. Maskaeva, and P. N. Ivanov, Hydrochemical Synthesis of Metal Sulfide Films: Modeling and Experiment (Ural Branch, Russian Academy of Sciences, Yekaterinburg, 2006) [in Russian].

2. V. G. Butkevich, V. D. Bochkov, and E. R. Globus, Prikl. Fiz., No. 6, 66 (2001).

3. M. S. Murashov, Kratk. Soobsch. Fiz., No. 12, 42 (1998).

4. A. S. Katysheva, V. F. Markov, I. V. Zarubin, et al., Vodnoe Khozyaistvo Rossii, No. 4, 64 (2011).

5. Yu. N. Makurin, R. N. Pletnev, D. G. Kleshchev, and N. A. Zhelonkin, Intermediate Complex in Chemical Reactions (Ural Branch, Academy of Sciences of the SSSR, Sverdlovsk, 1990) [in Russian].

6. S. G. Mokrushin and Yu. D. Tkachev, Kolloidn. Zh. 23, 438 (1961).

7. M. Dutt, D. Kameshwari, and D. Subbarao, Colloids Surf. A. Physicochem. Eng. Asp. 133, 89.

8. W. Kossel, Nachr. Ges. Wiss. Götting. Math. Phys. 2, 135 (1927).

9. I. N. Stranski, Z. Phys. Chem. 136, 259 (1928).

10. H. Frank, Obs. 14, 243 (1953).

11. A. E. Nielsen, Kinetics of Precipitation (Pergamon, Oxford, 1964).

12. V. F. Markov and L. N. Maskaeva, Butlerovskie Soobshch. 24 (2), 33 (2011).

13. J. Herrero, M. T. Gutierrez, C. Guillen, et al., Thin Solid Films 361-362, 28 (2000).

14. B. M. Smirnov, Physics of Fractal Clusters (Nauka, Moscow, 1991).

15. P. N. Ivanov, V. F. Markov, L. N. Maskaeva, and E. I. Stepanovskikh, Fundamental. Probl. Sovremennogo Materialoved. 2 (1), 29 (2005).

16. V. F. Markov and L. N. Maskaeva, Butlerovskie Soobshch. 24 (2), 42 (2011).

17. A. S. Katysheva, L. N. Maskaeva, A. V. Chukin, and V. F. Markov, Izv. Vyssh. Uchebn. Zaved., Khim. Khim. Tekhnol., Ser. Khim. 55, 87 (2012).

18. E. Feder, Fractals (Plenum, New York, 1988).

Translated by $O$. Fedorova 